\title{
Multiple shadows of firearm shot on the chest X-ray
}

Nika Kuridze ${ }^{1}$, Kakhaber Etsadashvili ${ }^{2}$, Khatuna Jalabadze ${ }^{3}$, Beka Rukhadze ${ }^{2}$, and Mikheil Tsverava ${ }^{1}$

${ }^{1}$ Ivane Javakhishvili Tbilisi State University

${ }^{2}$ G. Chapidze Emergency Cardiology Center

${ }^{3}$ Cardiology Clinic GULI

February 3, 2022

\begin{abstract}
In case of firearm shots, to choose an adequate treatment method, it's important to understand the nature of firearms and their projectiles. Residual results of an old firearm shot wound do not require additional intervention in the absence of symptoms.
\end{abstract}

\section{Hosted file}

Manuscript.doc available at https://authorea.com/users/458654/articles/555144-multipleshadows-of-firearm-shot-on-the-chest-x-ray

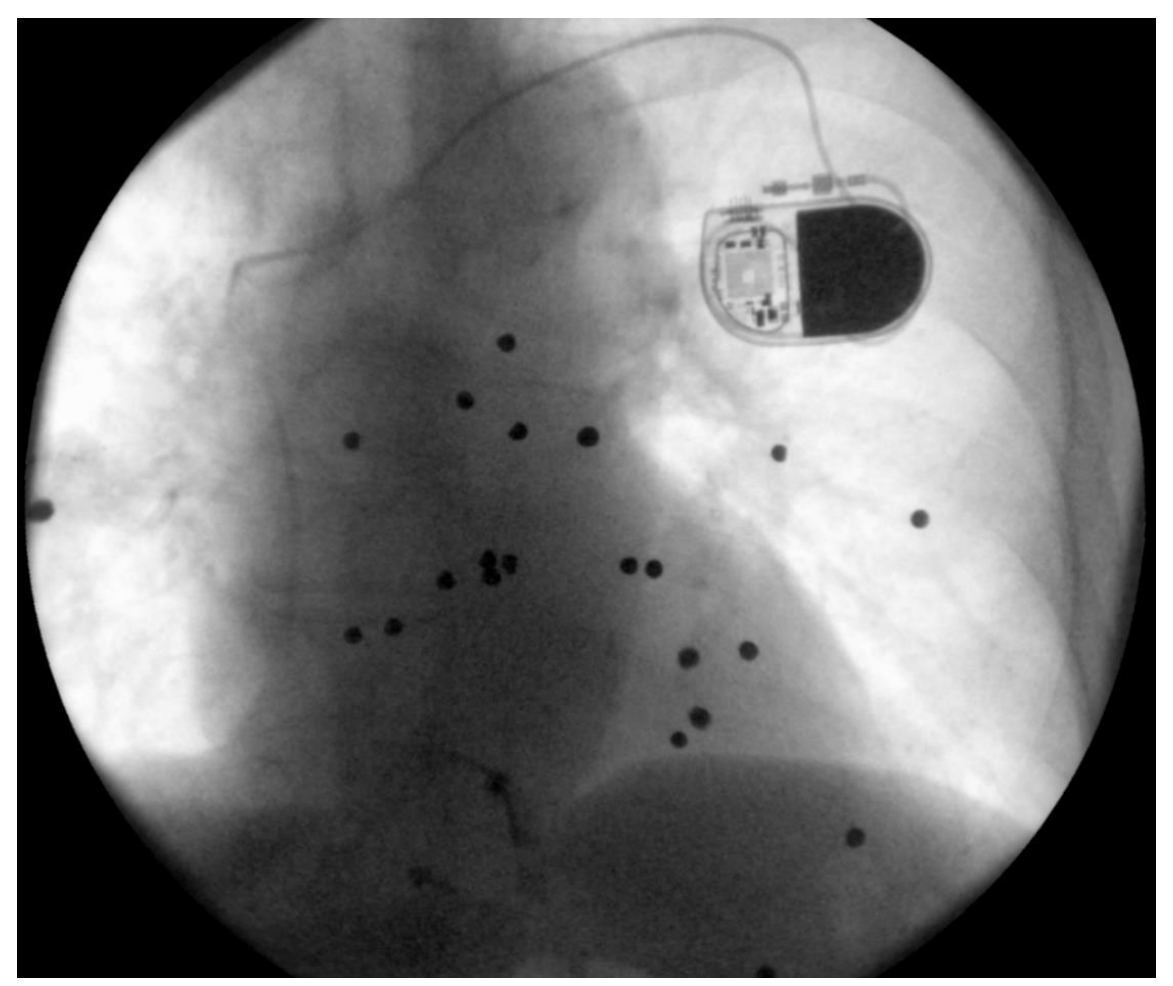

